\title{
DIAGNÓSTICO QUALITATIVO E QUANTITATIVO DA ARBORIZAÇÃO URBANA NO BAIRRO BIVAR OLINTO, PATOS, PARAÍBA
}

Rafael Rodolfo de Melo ${ }^{1}$, José Augusto de Lira Filho², Francisco Rodolfo Júnior ${ }^{3}$

\section{RESUMO}

Objetivou-se diagnósticar a arborização urbana qualitativa e quantitativamente do bairro Bivar Olinto, na cidade de Patos-PB. Foi realizado uma amostragem, sonteando aleatóriamente seis ruas, nas quais foram feitas um censo. Os dados foram coletados em um formulário padronizado, que continham informações sobre data de coleta, nomes da rua, nome do bairro, nome vulgar das espécies, fase de desenvolvimento, fitossanidade, problemas com a raiz, necessidade de poda, afastamento predial, altura total, altura da primeira bifurcação, diâmetro e situação das copas. Nas seis ruas inventariadas foram encontradas 164 plantas arbóreas, pertencentes a 12 espécies, sendo uma delas (Ficus bejamim) responsável por quase $70 \%$ dos indivíduos levantados. Das ruas estudas, Jose Mesquita e João Odorico apresentaram o maior percentual de indivíduos, 21,34\% e 20,73\% respectivamente. Já a Manuel Pereira filho demonstrou o menor percentual (12,20\%). A arborização do bairro foi considerada de forma geral como sadia, pois $88,47 \%$ das árvores apresentavam boas condições fitossanitárias. Mais de 90\% dos indivíduos obtiveram valores inferiores a cinco metros de altura e mais de 60\% inferiores a dez centímetros de diâmetro, o que caracteriza uma arborização relativamente jovem. Outras análises demonstraram ainda que a situação das fiações preocupante, quase $70 \%$ dos indivíduos as apresentavam acima das copas.

Palavras-chaves: Aborização urbana, florestas urbanas, diagnóstico, Patos-PB.

\footnotetext{
${ }^{1}$ Engenheiro Florestal, estudante de Pós-Graduação em Engenharia Florestal, Universidade Federal de Santa Maria, Centro de Ciências Rurais, Santa Maria, RS < rrmelo2@yahoo.com.br>.

2 Prof. Adjunto, Dr., Universidade Federal de Campina Grande, Centro de Saúde e Tecnologia Rural, Unidade Acadêmica de Engenharia Florestal, Campus de Patos, Patos, PB.

3 Prof. Substituto, M.Sc., Universidade Federal de Campina Grande, Centro de Ciências e Tecnologia Agroalimentar, Campus de Pombal, Pombal, PB <fcorodolfojunior@hotmail.com>.
} 


\title{
QUALITATIVE AND QUANTITATIVE DIAGNOSIS OF THE URBAN ARBORIZATION IN QUARTER BIVAR OLINTO, PATOS, PARAÍBA, BRAZIL
}

\begin{abstract}
The objective to predict the arborization urban qualitative and quantitative of the quarter Bivar Olinto, in the city of Patos. A sampling was carried through, drawing randomly six streets, in which they had been made a census. The data had been collected in a standardized form, that they contained information on date of collection, names of the street, name of the quarter, popular name of the species, phase of development, healthy, problems with the root, necessity of pruning, land removal, height, height of the first bifurcation, diameter and situation of the pantries. In the six inventoried streets 164 trees had been found, pertaining 12 species, being one of them (Ficus bejamim) responsible for almost $70 \%$ of the raised individuals. Of the streets you study, José Mesquita and João Odorico had presented the percentile greater of individuals, $21.34 \%$ and $20.73 \%$ respectively. Already the Manuel Pereira son demonstrated the percentile minor (12.20\%). The arborization of the quarter was considered of general form as healthy, therefore $88.47 \%$ of the trees presented good healthy conditions. More than $90 \%$ of the individuals had gotten inferior values the five meters of height and more than $60 \%$ inferiors the ten centimeters of diameter, what it characterizes a relatively young arborization. Other analyses had demonstrated despite the situation of the wirings preoccupying, almost $70 \%$ of the individuals presented them above of the pantries.
\end{abstract}

Key-Words: Urban arborization, urban forests, diagnosis, Patos-PB. 


\section{INTRODUÇÃO}

A arborização urbana, no Brasil, é considerada um tema recente, de evolução lenta e do qual as administrações públicas e a comunidade devem se envolver, cumprindo papéis distintos. Atualmente, em cidades onde ocorre o planejamento das arborizações, a preocupação é tornar o ambiente urbano diversificado quanto às espécies empregadas, mais homogêneo e envolvente com a paisagem circundante (MELO \& ROMANINI, 2005).

Entende-se por arborização urbana, o conjunto de terras públicas e privadas, com vegetação predominantemente arbórea que uma cidade apresenta, ou ainda, é um conjunto de vegetação arbórea natural ou cultivada que uma cidade apresenta em áreas particulares, praças, parques e vias públicas (SANCHOTENE, 1994; SILVA JÚNIOR \& MÔNICO, 1994). Segundo GONÇALVES (2000), atualmente o conceito de arborização urbana tem dado lugar a um conceito mais abrangente e a nova área do saber denominada "silvicultura urbana", por se entender que os agrupamentos de árvores são mais significativos que árvores isoladas.

A vegetação, como um todo, tem sido de grande importância na melhoria das condições de vida no meio urbano. Com o crescimento populacional das cidades, depara-se com a falta de um planejamento urbano. Segundo DANTAS \& SOUZA (2004), planejar a arborização é indispensável para o desenvolvimento urbano, para não trazer prejuízos para o meio ambiente. Além disso, a arborização é fator determinante da salubridade ambiental, por ter influência direta sobre o bem estar do homem, em virtude dos múltiplos benefícios que proporciona ao meio, em que além de contribuir à estabilização climática, embeleza pelo variado colorido que exibe, fornece abrigo e alimento à fauna e proporciona sombra e lazer nas praças, parques e jardins, ruas e avenidas de nossas cidades.

De acordo com GRAZIANO (1994), a vegetação urbana desempenha funções essenciais nos centros urbanos. Do ponto de vista fisiológico, melhora o ambiente urbano por meio da capacidade de produzir sombra; filtrar ruídos, amenizando a poluição sonora; melhorar a qualidade do ar, aumentando o teor de oxigênio e de umidade, e absorvendo o gás carbônico; amenizar a temperatura, entre outros aspectos.

GONÇALVES et al. (2002), afirma que a arborização urbana além da função paisagística proporciona inúmeros benefícios à população, entre eles destacam-se a proteção contra a ação dos ventos, diminuição da poluição sonora, absorção de parte dos raios solares, sombreamento, diminuição da poluição atmosférica neutralizando o excesso de dióxido de carbono purificando assim o ar, entre outros.

A arborização urbana no Brasil é uma atividade relativamente nova e tem sido realizada com raras exceções, sem planejamento. Neste contexto, a arborização de ruas 
requer para a efetivação dos benefícios esperados, que seja adequadamente planejada e mantida de forma sustentável (MILANO, 1994).

Para se conhecer a arborização urbana, é necessária a sua avaliação, o que depende da realização de inventário. O inventário da arborização tem como objetivo geral conhecer o patrimônio arbustivo e arbóreo de uma localidade. Tal levantamento é fundamental para o planejamento e manejo da arborização, fornecendo informações sobre a necessidade de poda, tratamentos fitossanitários ou remoção e plantios, bem como para definir prioridades de intervenções. Para TAKAHASHI (1994), a importância do inventário está no fato de que através dele pode-se conhecer o patrimônio arbóreo e identificar as necessidades de manejo. Um dos aspectos mais importantes do inventário é quando este é realizado de forma a fornecer uma contínua atualização das informações.

O tipo de inventário utilizado deverá ser em função dos objetivos especificamente definidos, fundamentados em diferentes metodologias e graus de precisão (TAKAHASHI, 1994; MOTTA, 1998; COSTA \& HIGUCHI, 1999; MILANO \& DALCIN, 2000). Segundo MILANNO (1994), os inventários podem ser por amostragem ou inventário total. Este último é mais direcionado para locais onde a freqüência da arborização é muito heterogênea entre vias públicas ou bairros, ou em cidades de pequeno porte, conforme utilizado por ROBAYO (1993), TEIXEIRA et al. (1994), COSTA et al. (1996) e SILVA (2000).

Segundo SILVA et al. (2006), as características e parâmetros a serem avaliados devem abordar alguns pontos básicos, como a localização da árvore (nome da rua, bairro, número da casa), características da árvore (espécie, porte, fitossanidade) e características do meio (largura de ruas e passeios, espaçamento do plantio, pavimentação dos passeios, presença de redes de serviços, afastamento predial, tipo de forração na área de crescimento).

A presença de áreas verdes, urbanas ou não, tem sido objeto de estudos por diferentes grupos e instituições, desde o simples levantamento e mapeamento de espécies (ROBAYO, 1993; TAKAHASHI, 1994; TEXEIRA et al., 1994; GONÇALVES et al., 1998; MOTTA, 1998; CARDOSO-LEITE et al..1999; COSTA \& HIGUCHI, 1999; MEDEIROS et al.,1999; SANTANA \& SANTOS, 1999; SILVA, 2000; DANTAS \& SOUZA, 2004; SILVA et al., 2006), ou a identificação das espécies com enfoque na educação ambiental ou trilha ecológica (DIAS et al., 1999; FAVERO et al., 1999) até o resgate do papel social da vegetação para o bem-estar do homem e a melhoria da qualidade de vida (SILVA JÚNIOR \& MÔNICO, 1994; ROCHA et al., 2004; MARENZI, 1999). Neste sentido, o presente trabalho teve como objetivo realizar um diagnostico qualitativo e quantitativo da arborização urbana do bairro Bivar Olinto, na cidade de Patos-PB. 


\section{MATERIAIS E MÉTODOS}

\section{Área de Estudo}

O estudo foi realizado no bairro Bivar Olinto na cidade de Patos. A cidade de Patos está situada na região Semi-Árida do Nordeste brasileiro, no Estado da Paraíba a cerca de 320 km da Capital, João Pessoa. Apresenta as coordenadas $7^{\circ} 01^{\prime} \mathrm{S} 37^{\circ} 17^{\prime} \mathrm{W}$, a 250m de altitude. A temperatura média anual é de $27^{\circ} \mathrm{C}$, as médias mensais variando pouco entre si. A pluviosidade média é de $728 \mathrm{~mm} / \mathrm{ano}$, sendo irregularmente distribuída entre os meses, com maior incidência entre os meses de fevereiro a abril, mas, com grandes variações de ano para ano (PARAÍBA, 1985).

O bairro Bivar Olinto caracteriza-se em sua maioria como residencial. É um bairro jovem, com aproximadamente 15 anos, sendo um dos únicos a serem planejados da cidade.

\section{Inventário}

O método de inventário utilizado no levantamento foi em forma de amostragem. Para isso, foram sorteadas aleatoriamente de seis ruas (João Odorico, José Mesquita, Manoel Pereira Filho, Semeão Gentio, Vereador Robson Rodrigues e Zózemo Dantas Gurgel). Para cada uma delas foi realizado o censo, também denominado inventário total, onde foram coletados dados de caráter quali-quantitativo.

Os dados foram coletados em junho de 2005, em formulário específico, com informações sobre a data de coleta, nomes da rua ou logradouro, bairro, setor e o número de quadras sorteadas.

Quanto às informações sobre as árvores, foram coletados o nome vulgar, fase de desenvolvimento, fitossanidade, problemas com a raiz, necessidade de poda, afastamento predial, altura total, altura da primeira bifurcação, diâmetro e situação das copas (Figura 1).

\section{Avaliações}

A diversidade de espécies foi avaliada, assim como seu desenvolvimento, sendo classificadas como jovens ou adultas. Com base nos dados, pode-se avaliar a homogeneidade da arborização do bairro. 


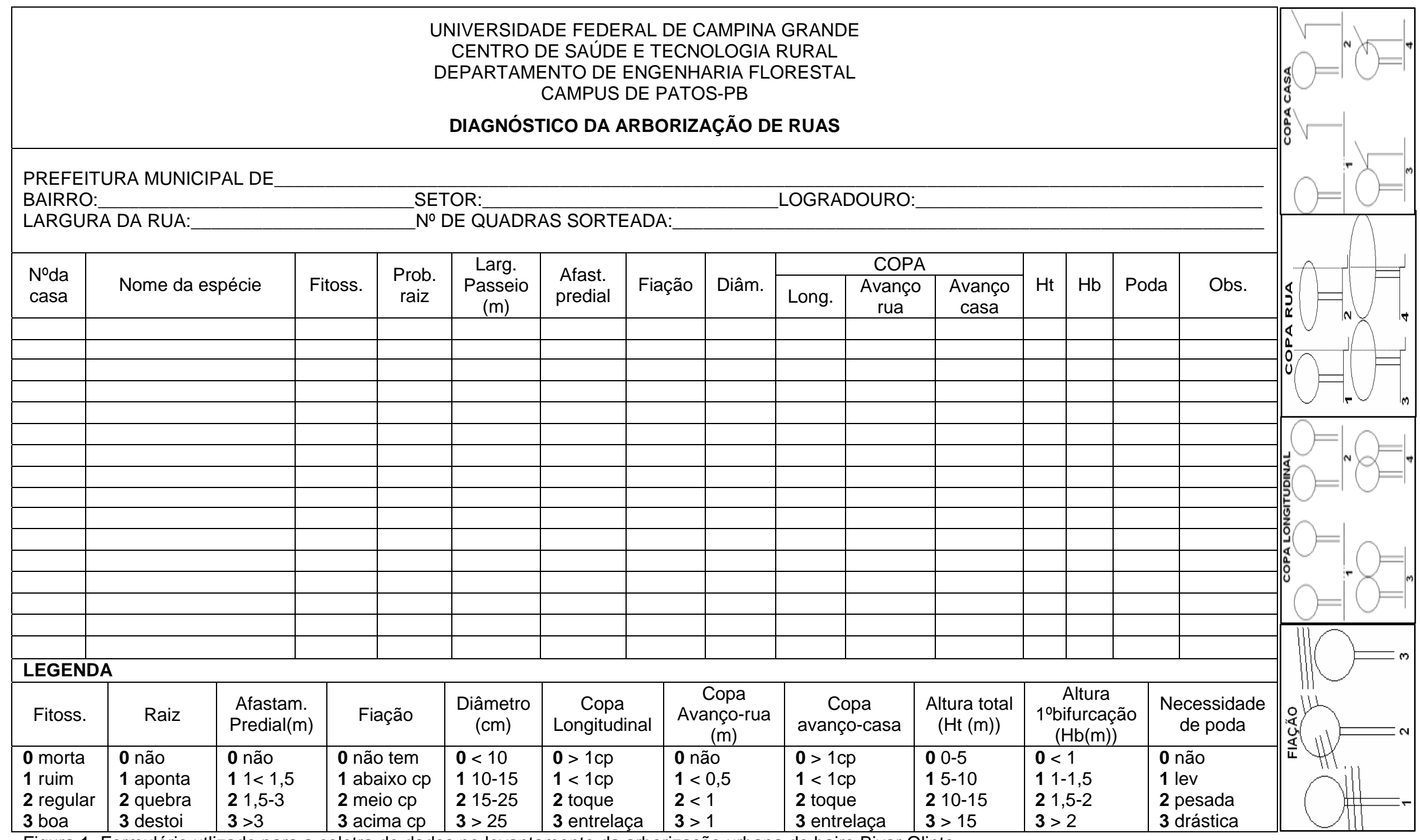

Figura 1. Formulário utlizado para a coletra de dados no levantamento da arborização urbana do bairo Bivar Olinto. 
As condições da sanidade das árvores foram analisadas conforme as seguintes categorias: morta - apresenta danos irreversíveis de pragas, doenças ou graves danos físicos; ruim - apresenta estado geral de declínio que podem ser severos danos de pragas, doenças ou defeitos físicos e, não aparentando morte iminente, podendo requerer muito trabalho e tempo para a recuperação; regular - apresenta condições e vigor médios, mostrando sinais de pragas doenças ou danos físicos, necessitando de poda corretiva, reparo de danos físicos ou controle sanitário; boa - vigorosas e que não apresenta sinais de pragas doenças ou injurias mecânicas.

Com relação aos problemas da raiz em condições externas, as espécies foram codificas em quatro categorias, foram elas: nenhum - raiz não se encontra exposta; aponta raiz está apontando na superfície do solo; quebra - a raiz se expõe na superfície e apresenta sinais de quebra no passeio ou na rua; destrói - ao emergir na superfície quebra a estrutura superficial.

De acordo com a necessidade de podas, levaram-se em considerações os seguintes aspectos: nenhuma - não há necessidade de poda no momento atual; leve - árvore necessita de uma poda leve para manutenção; pesada - necessidade de poda pesada; drástica - em virtude de danos ou outros problemas apresentados necessita de uma poda drástica.

Procurou-se também, diagnosticar a situação das copas das árvores a partir dos seguintes parâmetros: copa longitudinal - permite-se averiguar se o espaçamento utilizado no plantio foi adequado; avanço na rua - possibilidade de causar sérios problemas para o tráfego local; avanço para o prédio - geração de problemas para os moradores da cidade, que vão desde a falta de segurança até a diminuição da iluminação natural.

Também foram avaliados o afastamento predial, parâmetro que diz respeito ao distanciamento entre a árvore e a construção dentro do lote, sobretudo na posição frontal. $\mathrm{Na}$ avaliação da arborização urbana a posição frontal da construção predial tem grande influência na escolha das espécies a serem plantadas.

Foi considerado o tamanho das árvores, sendo isto feito de forma visual e aproximada, utilizando parâmetros de alturas conhecidas como postes e casas. Já com relação à primeira bifurcação, foi utilizada uma fita métrica para medição do solo até este ponto.

\section{RESULTADOS E DISCUSSÃO}

\section{Características das Ruas, Abundância e Diversidade de Espécies}

Ao analisar a Tabela 1, é visto que as ruas apresentaram larguras variando entre 7,00 a 14,00m e passeio entre 1,80 a 2,90m. De acordo com a CEMIG (2001) as ruas com 
larguras superiores $7,00 \mathrm{~m}$ e passeios superiores a 2,00m são consideradas largos. Portanto, percebe-se que todas as ruas são consideradas de ruas largas, e entre os passeios, apenas os passeios das ruas José Mesquita e Manuel Pereira Filho e considerado estreito, por apresentarem $1,90 \mathrm{~m}$ e $1,95 \mathrm{~m}$ respectivamente.

Tabela 1. Ocorrência de árvores por ruas amostradas e larguras das ruas e passeios

\begin{tabular}{|c|c|c|c|c|}
\hline Rua & Rua (m) & Passeio (m) & $\mathbf{N}^{\circ}$ & $(\%)$ \\
\hline José Mesquita & 7,00 & 1,90 & 35 & 21,34 \\
\hline João Odorico & 7,00 & 2,50 & 34 & 20,73 \\
\hline Zózemo Dantas Gurgel & 7,90 & 1,95 & 29 & 17,68 \\
\hline Semeão Gentil & 8,00 & 2,00 & 24 & 14,63 \\
\hline Vereador Robson Rodrigues & 8,00 & 2,90 & 22 & 13,41 \\
\hline Manuel Pereira Filho & 14,00 & 1,80 & 20 & 12,20 \\
\hline Média \pm Desvio Padrão & $8,65 \pm 2,43$ & $2,18 \pm 0,39$ & $27,33 \pm 5,76$ & $16,65 \pm 3,51$ \\
\hline TOTAL & - & - & 164 & 100,00 \\
\hline
\end{tabular}

No geral, as ruas apresentaram uma largura média de $8,65 \pm 2,43 \mathrm{~m}$ e os passeios de $2,18 \pm 0,39 \mathrm{~m}$, ambos os resultados apresentaram valores considerados como largos pela CEMIG (2001).

Ainda na Tabela 1, observa-se que houve grande diferença quanto ao ocorrência de árvores em cada rua, sendo a José Mesquita (21,34\%) e João Odorico $(20,73 \%)$ as que apresentaram os maiores quantidades de individuos. Vereador Robson Rodrigues $(13,41 \%)$ e Manuel Pereira Filho $(12,20 \%)$ apresentaram menor percentual de indivíduos. As demais ruas ocuparam posições intermediárias.

Nas ruas do bairro Bivar Olinto estudadas, foram encontradas 164 plantas arbóreas, pertencentes a 12 espécies, sendo apenas uma delas, o Fícus bejamin, responsável por quase $70 \%$ dos indivíduos levantados (Tabela 2 ). 
Tabela 2. Espécies ocorrentes no bairro Bivar Olinto, com os seus respectivos nomes científicos, quantidade de indivíduos encontrados e ocorrência (\%)

\begin{tabular}{|c|c|c|c|}
\hline Nome Vulgar & Nome Científico & $\mathbf{N}^{\mathbf{0}}$ & (\%) \\
\hline Algaroba & Prosopis juliflora (Sw.) DC. & 4 & 2,44 \\
\hline Brasileirinho & Erythrina indica-picta (L.) B. \& M. & 2 & 1,22 \\
\hline Cassia (1) & Cassia ferruginea Schrad. ex DC. & 2 & 1,22 \\
\hline Cassia (2) & Cassia seamea $L$. & 23 & 14,02 \\
\hline Craibeira & Tabebuia áurea (Mart.) Bureau. & 1 & 0,61 \\
\hline Esponja & Acacia farnesiana (L.) Willd. & 2 & 1,22 \\
\hline Ficus & Ficus Bejamin L. & 114 & 69,51 \\
\hline Flaboyam & Delonix regia (Hook.) Raf. & 2 & 1,22 \\
\hline Linhaça & Linum usitatissimum L. & 1 & 0,61 \\
\hline Sete-copas & Terminalia catappa $L$. & 11 & 6,71 \\
\hline Tamarindo & Tamarindus indica $L$. & 1 & 0,61 \\
\hline Tamboril & Enterolobium contortisiliquum (Vell.Conc.) & 1 & 0,61 \\
\hline TOTAL & 12 espécies & 164 & 100,00 \\
\hline
\end{tabular}

Alguns autores, dentre eles GREY \& DENEKE (1986) e MILANO \& DALCIN (2000), afirmam que cada espécie não deve ultrapassar 15\% do total de indivíduos da população arbórea, para um bom planejamento da arborização urbana. Dentro desse aspecto, o Ficus Bejamin foi à espécie predominante, fugindo às recomendações desses autores. A predominância de apenas uma espécie ou grupo de espécies pode facilitar a propagação das pragas, atualmente muito comum nas árvores em ambiente urbano.

Entretanto, SILVA (2000) relata que é comum na arborização urbana, que poucas espécies representem a maior parte da população, mesmo não sendo uma situação desejável, quer por razões estéticas ou fitossanitárias. Uma concentração maior de indivíduos distribuídos num pequeno número de espécies também foi encontrada por LIMA et al. (1994), MILANO (1994) e SILVA et al. (2006), mas, em nenhum desses casos com uma predominância tão grande como a encontrada neste trabalho.

Além disso, a relatos que o Fícus bejamin é prejudicial à estrutura viária da cidade, sendo observados danos a calçadas, calçamento e conflitos com as redes aéreas, embora tais observações não tenham sido detalhadas neste estudo. SANTANA \& SANTOS (1999) comentaram que o gênero Ficus é causador de problemas como elemento de arborização no Campus da Universidade Estadual de Feira de Santana (UEFS), por danificar calçadas.

Após o ficus, a espécie que apresentou maior número de individuos foi a Cassia seamea (14,02\%), árvore bastante comum na arborização urbana do Estado. As outras espécies juntas, somam apenas $16,47 \%$ dos individuos encontrados no levantameto. 


\section{Situação das Copas}

As diferentes condições da copa (Tabela 3) nos mostram que para a copa longitudinal a maioria das árvores $(67,68 \%)$ apresentava uma boa distância entre a suas copas (> 1 copa). Outros dados que deve ser evidenciados é que 9,15\% das copas se tocavam e que $9,76 \%$ estavam entrelaçadas.

Tabela 3. Situação das copas quanto os avaços longitudinal, para a rua e para a casa.

\begin{tabular}{crrrrrr}
\hline \multirow{2}{*}{ Classe } & \multicolumn{2}{c}{ Copa Longitudinal } & \multicolumn{2}{c}{ Copa Rua } & \multicolumn{2}{c}{ Copa Casa } \\
\cline { 2 - 7 } & \multicolumn{1}{c}{$\mathbf{N}^{\mathbf{0}}$} & $\mathbf{( \% )}$ & $\mathbf{N}^{\mathbf{0}}$ & $\mathbf{( \% )}$ & $\mathbf{N}^{\mathbf{0}}$ & $\mathbf{( \% )}$ \\
\hline I & 111 & 67,68 & 92 & 56,10 & 120 & 73,17 \\
II & 22 & 13,41 & 41 & 25,00 & 26 & 15,85 \\
III & 15 & 9,15 & 10 & 6,10 & 11 & 6,71 \\
IV & 16 & 9,76 & 21 & 12,80 & 7 & 4,27 \\
\hline TOTAL & $\mathbf{1 6 4}$ & $\mathbf{1 0 0 , 0 0}$ & $\mathbf{1 6 4}$ & $\mathbf{1 0 0 , 0 0}$ & $\mathbf{1 6 4}$ & $\mathbf{1 0 0 , 0 0}$ \\
\hline
\end{tabular}

P/ avanço da copa longitudinal e copa casa: I >1copa; II < 1copa; III toque; IV entrelaçadas;

P/ avanço da copa rua: I ñ há avanço; II <0,5m; III 0,5-1m; IV > 1m.

Quanto ao avanço das copas a rua, constatou-se que a maior parte $(56,10 \%)$ não apresentava nenhum avanço. O mesmo foi constato para o avanço a casa, chegando ao valor de $73,17 \%$. Porém para 15,85 existe uma distância de menor que 0,5 metros entre a casa e a copa das árvores.

\section{Características Altimétricas e Diâmetricas das Árvores}

Na Figura 2 encontram-se as informações de altura total das árvores $(\mathrm{Ht})$, altura da primeira bifurcação $(\mathrm{Hb})$ e diâmetro a altura do peito (DAP) das árvores em diferentes classes. A classe I, equivale a árvores de 0-5 m, menor que $1 \mathrm{~m}$ e menor que $10 \mathrm{~cm}$, a classe II de 5-10 m, 1-1,5 m e 10-15 cm, a classe III de 10-15 m, 1,5-2 m e 15-25 cm e a classe IV maior que $15 \mathrm{~m}$, maior que 2 e maior $25 \mathrm{~cm}$, para $\mathrm{Ht}$, $\mathrm{Hb}$ e DAP respectivamente. 


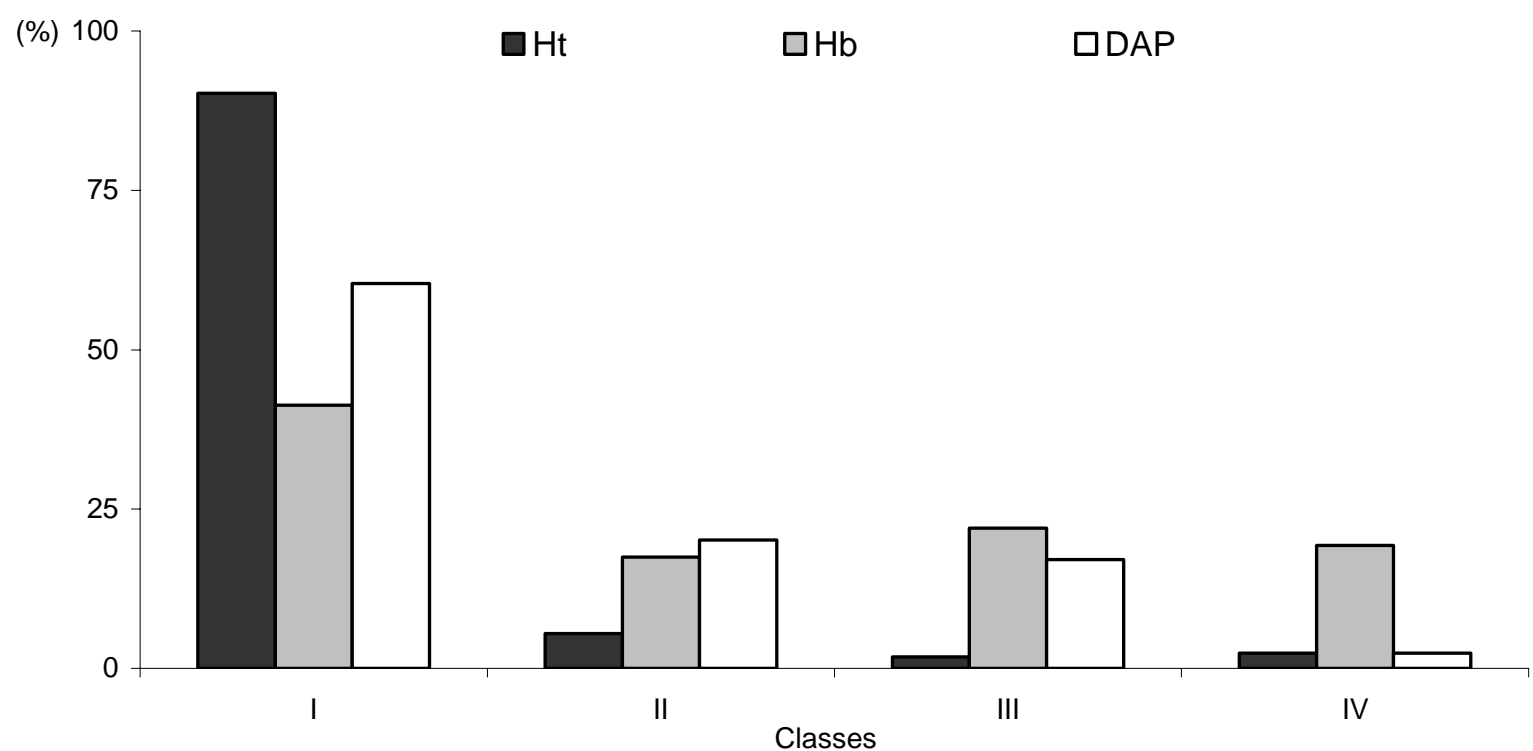

Figura 2. Altura total $(\mathrm{Ht})$, altura da primeira bifurcação $(\mathrm{Hb})$ e diâmetro a altura do peito (DAP) das árvores.

$\mathrm{Na}$ altura total das árvores é visto que mais de 90\% delas apresentavam crescimento entre menor que $5 \mathrm{~m}$, evidenciando que as plantas são muito jovens. Apenas $5,49 \%$ das árvores encontravam-se com altura entre 5 e 10m, 1,83\% entre 10 e $15 \mathrm{~m}$ e 2,44\% apresentavam altura superior a 15m. Isso se explica por ser o Bivar Olinto um bairro jovem e consequentemente possuidor de árvores jovens em sua maioria. Além disso, o próprio clima da região interfere negativamente no processo desenvolvimento das árvores, fazendo-o com que seja mais demorado. Estudos realizados por ROCHA et al (2004) em dois bairros de Nova Iguaçu, no Rio de Janeiro, foram observados que $64,3 \%$ e $51,1 \%$ das árvores de cada bairro apresentavam altura inferior a $6 \mathrm{~m}$ e $10,1 \%$ e 18,2\% das árvores tinham altura superior a $8,8 \mathrm{~m}$.

Com relação à altura da primeira bifurcação, pouco mais de $20 \%$ das árvores apresentavam a altura considera ideal para facilitar a passagem de pedestres $(2 \mathrm{~m})$. Este resultado mostra que deve ser realizada uma condução das plantas utilizadas na arborização urbana, para que estas não venham a possuir problemas semelhantes no futuro.

Cerca de $60 \%$ dos DAP das árvores analisadas foram inferior a $10 \mathrm{~cm}$, o que reforça inda mais juventude da arborização deste bairro. Para 20,12\% das árvores o DAP encontrava-se entre 10 e 15cm, 17,10\% entre 15 e $25 \mathrm{~cm}$ e apenas 2,44\% demonstraram diâmetro superior a $25 \mathrm{~cm}$. 


\section{Situação das Árvores Avaliadas}

A situação das árvores avaliadas quanto à fase de desenvolvimento, necessidade de podas, situção das copas quanto à fiação, afastamenta das árvores com relação aos imóveis, problemas ocasionados pelas raizes e sanidade encontram-se na Figura 3.

Observa-se a predominância de árvores adultas em relação às árvores jovens. Aproximadamente $69 \%$ das árvores componentes da arborização foram consideradas como adultas no levantamento (Figura 1.A).

$\mathrm{Na}$ análise da necessidade de poda, 67,68\% indivíduos não necessitavam de poda. Isto se deu devido cuidados tomados pelos moradores do bairro, pois durante o estudo foram observados que esses moradores se preocupam ao com as árvores que se encontravam em frente a sua casa, tendo certo zelo, podando-as, aguando-as e adubandoas. No entanto, para $29,27 \%$ das árvores havia necessidade de uma poda leve (também chamada poda de formação ou de limpeza) enquanto que, apenas 3,05\% necessitavam de uma poda pesada. Não houve casos em que fosse considerada a necessidade de poda drástica (Figura 1.B).

O plantio de árvores nas cidades deve ser compatibilizado com a fiação aérea existente na malha urbana. Segundo a CEMIG (2001), o plantio sob fiação deverá ser feito com árvores de pequeno porte em posição alternada com a arborização do outro lado da rua. Para o Bivar Olinto, pode-se ver que para mais de 30\% indivíduos não existam fiações perto das copas. Já para aproximadamente 13\%, apresentavam fiações entre as copas e quase $70 \%$ das copas apresentam fiações por acima, o que é um grave problema, que pode até chegar a afetar o abastecimento de energia elétrica da região, necessitando de podas periódicas (Figura 1.C).

As espécies encontradas na arborização do bairro, mencionadas na Tabela 1, são de médio e grande porte, o que detecta-se é que as mesmas implantadas erroneamente nas ruas, necessitando de correções. Vala salientar que há um considerável número de espécimes jovens que acarretarão problemas futuros para a fiação. Observa-se também (Figura 2.D), que aproximadamente 65\% das espécies apresentam afastamento maior que 3,5m e 8\% chegar a tocar os imóveis não apresentando afastamento algum.

Em poucos casos, foram verificados problemas de raiz nas ruas do bairro. Para $12 \%$ dos indivíduos as raízes apontam e pouco mais de 4\% quebram ou destroem a estrutura superficial (Figura2.E). Analisando as condições fitossanitárias da arborização das ruas (Figura 3.F), observa-se que $88,47 \%$ das árvores se encontram em bom estado, 7,68\% em condições regular e apenas $3,85 \%$ em condições ruins. Não houve casos de árvores mortas ou em fases terminais irreversíveis. 

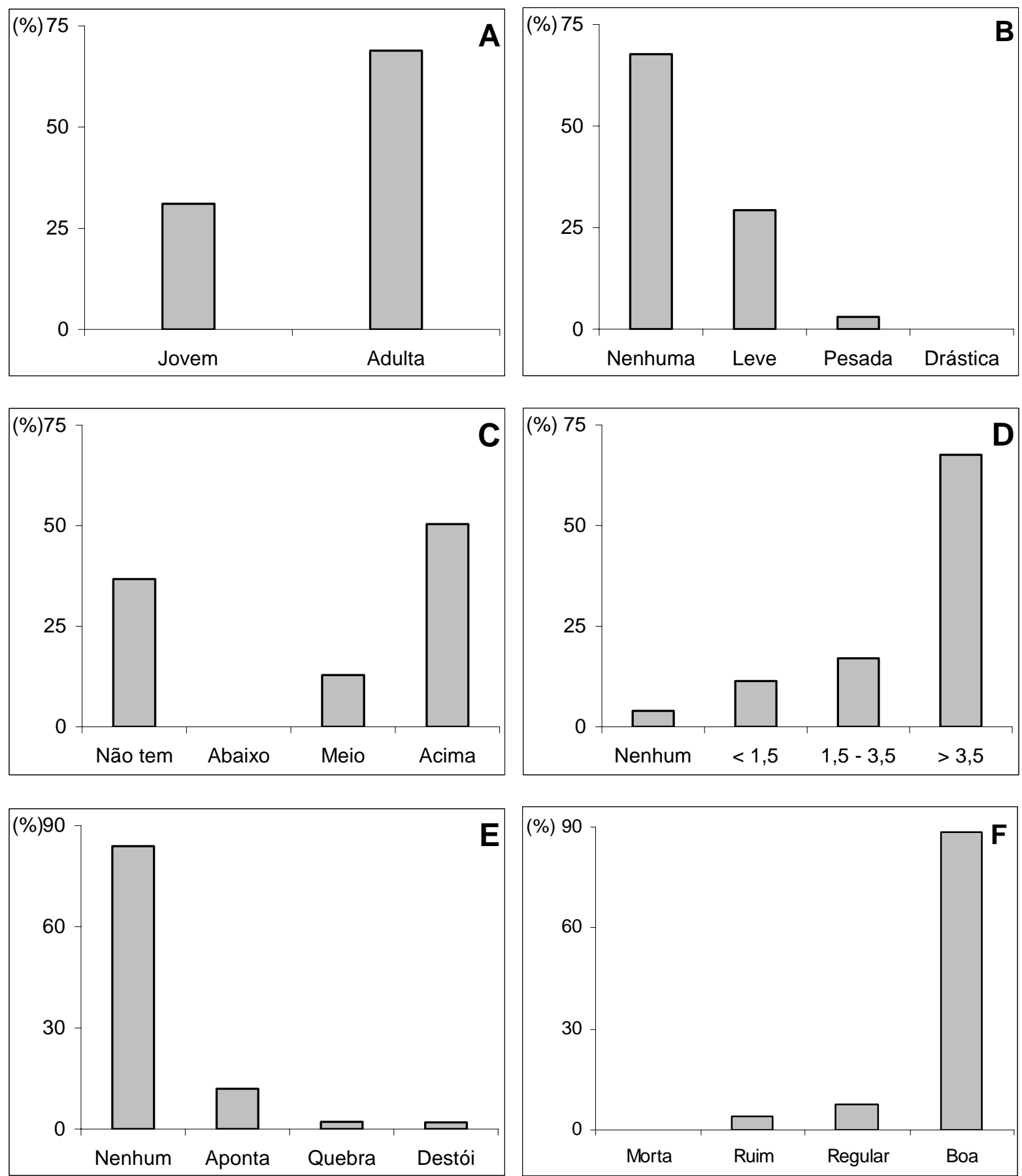

Figura 3. Situação das árvores avaliadas do bairro Bivar Olinto, quanto a(o) A. Fase de desenvolvimento; B. Necessidade de podas; C. Situção das copas quanto à fiação; D. Afastamenta das árvores com relação aos imóveis; E. Problemas ocasionados pelas raizes; F. Sanidade. 


\section{CONCLUSÕES}

O bairro residencial Bivar Olinto demonstrou que a maior parte dos indivíduos que compõe sua arborização não necessitava de podas e encontrava-se em boas condições fitossanitárias.

Algumas das situações inadequadas e constantemente presentes em conflitos da arborização urbana, avanço da copa a rua, avanço da copa a casa, entrelaçamentos de copas (copa longitudinal), larguras das ruas e passeios, problemas ocasionados pela raiz e afastamento das árvores com relação aos imóveis ocorreram em poucos casos, não chegando a números consideráveis.

Houve uma baixíssima diversidade de indivíduos na arborização do bairro, tendo apenas uma espécie, o Ficus bejamim, uma porção 70\% das árvores inventariadas, o que se torna grave, podendo uma única praga e/ou doença prejudicar toda a arborização. A situação das fiações também é preocupante, quase 70\% dos indivíduos as apresentavam acima das copas, estando boa parte dos indivíduos em fase de crescimento isto pode acarretar vários problemas futuramente.

\section{REFERÊNCIAS BIBLIOGRÁFICAS}

CARDOSO-LEITE, E. et al. Mapeamento da Vegetação de uma Reserva Biológica no Sudeste do Brasil, Através de Fotointerpretação e Levantamento de Campo, Como Subsídio ao seu Zoneamento e Conservação. In: CONGRESSO NACIONAL DE BOTÂNICA, 50, Blumenau, 1999. Anais... Blumenau: Sociedade Botânica Brasileira, 1999. p.149.

CEMIG - COMPANHIA ENERGÉTICA DE MINAS GERAIS. Manual de arborização. Belo Horizonte: Superintendência do Meio Ambiente/CEMIG, 2001. 40p.

COSTA, L. A.; HIGUCHI, N. Arborização de ruas de Manaus: avaliação qualitativa e quantitativa. Revista Árvore, v. 23, n. 2, p. 223-232, 1999.

costA, L. M. S. A.; et al. Arborização das ruas do Bairro de Copacabana. In: CONGRESSO BRASILEIRO DE ARBORIZAÇÃO URBANA, 3., 1996, Salvador. Anais... Salvador: Sociedade Brasileira de Arborização Urbana, 1996. p.79-88.

DANTAS I.C. \& SOUZA, C.M.C. Arborização urbana na cidade de Campina Grande-PB: Inventário e suas espécies. Revista de Biologia e Ciências da Terra. v.4, n.2, 2004. 
DIAS, Adriana et al. Programa piloto de Educação Ambiental na trilha do Jacatirão, llha de Santa Catarina, Florianópolis. In: CONGRESSO NACIONAL DE BOTÂNICA, 50, Blumenau, 1999. Anais... Blumenau: Sociedade Botânica Brasileira, 1999. p.151.

FAVERO, O.A.; TAMAZATO, M.S.; IWAKI, N.C.; MOREIRA, P.G.; SIENA, L.V.P.; NASCIMENTO, G.C. Elaboração de roteiro ecoturistico para a trilha da Pedra Santa, Floresta Nacional de Ipanema, Iperó-SP. In: CONGRESSO NACIONAL DE BOTÂNICA, 50, Blumenau, 1999. Anais... Blumenau: Sociedade Botânica Brasileira, 1999. p.149.

GONÇALVES, F.C.C. et al. Análise Pós-Ocupação de uma Praça de Burle Marx em Recife. In: CONGRESSO NACIONAL DE BOTÂNICA, 49, Salvador, 1998. Anais... Salvador: Sociedade Botânica Brasileira, 1998. p.265.

GONÇALVES, W. et al. Plano de arborização urbana de Itaguara-MG. Viçosa-MG, 2002. $36 \mathrm{p}$.

GONÇALVES, W. Florestas urbanas. Ação ambiental, Ano II, n.9, p.17-19, 2000.

GRAZIANO, T. T. Viveiros Municipais. Departamento de Horticultura - FCAVJ - UNESP. Notas de Aula, 1994.

GREY, G. W., DENEKE, F. J. Urban forestry. New York, John Wiley \& Sons, 1986. 279 p.

LIMA, A. M. L. P., COUTO, H. T. Z., ROXO, J. L. C. Análise de espécies mais freqüentes da arborização viária, na zona urbana central do município de Piracicaba-SP. In: CONGRESSO BRASILEIRO DE ARBORIZAÇÃO URBANA, 2, 1994, São Luis. Anais... São Luís, 1994. p.555-573.

MARENZI, R.C. A influência da Vegetação nas Preferências Paisagísticas no Município da Penha. In: CONGRESSO NACIONAL DE BOTÂNICA, 50, Blumenau, 1999. Anais... Blumenau: Sociedade Botânica Brasileira ,1999. p.150.

MEDEIROS, João de Deus et al. A Vegetação do Parque Florestal do Rio Vermelho. In: CONGRESSO NACIONAL DE BOTÂNICA , 50, Blumenau, 1999. Anais... Blumenau: Sociedade Botânica Brasileira ,1999. p.150.

MELO, E.F.R.Q.; ROMANINI, A. Importância da praça na arborização urbana. In: CONGRESSO BRASILEIRO DE ARBORIZAÇÃO URBANA, 9, 2005, Belo Horizonte. Anais... São Luís: Sociedade Brasileira de Arborização Urbana, 2005, 12p., CD-ROM. 
MILANO, M.; DALCIN, E. Arborização de vias públicas. Rio de Janeiro: LIGHT, 2000. $226 p$.

MILANO, M.S. Métodos de amostragem para avaliação de ruas. In: Congresso Brasileiro sobre Arborização Urbana, 2, São Luiz, 1994. Anais... São Luiz: SBAU, 1994. p.163-168.

MOTTA, G. L. O. Inventário da arborização de áreas, utilizando um sistema hierárquico para endereço impreciso. 1998. 120 f. Dissertação (Mestrado em Ciências Florestais) Universidade Federal de Viçosa, Viçosa, 1998.

PARAÍBA. Atlas geográfico do Estado da Paraíba. Secretaria de Educação, Governo do Estado da Paraíba/Universidade Federal da Paraíba. 1985.

ROBAYO, J. A. M. Inventário da arborização de ruas. In: CURSO de arborização urbana Curitiba: Universidade Livre do Meio Ambiente, 1993. p. 82-92.

ROCHA, R.T.; LELES, P.S.S.; OLIVEIRA NETO, S. Arborização de vias públicas em Nova Iguaçu, RJ: o caso dos bairros rancho novo e centro. Revista Árvore, Viçosa,MG, v.28, n.4, p.599-607, 2004.

SANCHOTENE, M. do C.C. Desenvolvimento e perspectivas da arborização urbana no Brasil. In: Congresso Brasileiro de Arborização Urbana, 2, 1994. São Luís-MA. Anais... São Luís, Sociedade Brasileira de Arborização Urbana; 1994.

SANTANA, J.R.F.; SANTOS, G.M.M. Arborização do campus da UEFS: exemplo a ser seguido ou um grande equívoco? Sitientibus, n.20, p.103-107, 1999.

SILVA JÚNIOR, O. A. B. da \& MÔNICO, M. O. M. Arborização em Harmonia com a Infraestrutura Urbana. In: $\mathbf{1}^{\text {a }}$ Semana de Meio Ambiente. Prefeitura Municipal de Guarulhos: Secretaria de Meio Ambiente, 1994.

SILVA, A. G. Arborização urbana em cidades de pequeno porte: avaliação quantitativa e qualitativa. 2000. 150f. Dissertação (Mestrado em Ciências Florestais), Universidade Federal de Viçosa, Viçosa, 2000.

SILVA, A.G.; GONÇALVES, W.; LEITE, H.G.; SANTOS E. comparação de três métodos de obtenção de dados para avaliação quali-quantitativa da arborização viária, em Belo Horizonte-MG. Revista da Sociedade Brasileira de Arborização Urbana, v.1, n1, 2006, p.31-44. 
TAKAHASHI, L. Y. Arborização urbana: inventário. In: CONGRESSO BRASILEIRO DE ARBORIZAÇÃO URBANA, 2., 1994, São Luís. Anais... São Luís: Sociedade Brasileira de Arborização Urbana, 1994. p.193-200.

TEIXEIRA, I. F.; SANTOS, N. R. Z. S.; HURTADO, R. R. Avaliação da vegetação das ruas e áreas verdes dos loteamentos da Cidade de Santa Maria-RS. In: CONGRESSO BRASILEIRO DE ARBORIZAÇÃO URBANA, 2., 1994, São Luís. Anais... São Luís: Sociedade Brasileira de Arborização Urbana, 1994. p.389-401. 